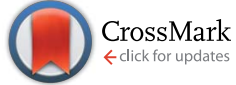

Cite this: RSC Adv., 2015, 5, 78030

Received 13th August 2015

Accepted 4th September 2015

DOI: $10.1039 / c 5 r a 16340 d$

www.rsc.org/advances

\section{Preparation and analysis of a new bioorganic metallic material}

\author{
P. Cao, ${ }^{a}$ C. Q. Yuan, ${ }^{\star a}$ C. Y. Ma, ${ }^{a}$ Y. Yang, ${ }^{\text {b X. Q. Bai, }}{ }^{a}$ X. J. Wang, ${ }^{a}$ X. Y. Ren, ${ }^{a} H . \mathrm{Xie}^{\mathrm{c}}$ \\ and X.P. Yan ${ }^{a}$
}

Biofouling on metal surfaces is one of the main reasons for increased ship drag. Many methods have already been used to reduce or remove it with moderate success. In this study, a synthetic peptide has been utilized to react with 304 stainless steel aiming to generate a bioorganic stainless steel using a facile technique. After the reaction, white matter was found on the surface of the treated stainless steel via SEM, whilst the nontreated stainless steel had none. Elemental analysis confirmed that excessive $\mathrm{N}$ existed on the surface of the treated samples using an integrated SEM-EDS instrument, implying the presence of peptides binding on the surface of the bioorganic stainless steel. The FTIR spectra showed amide A and II peaks on the surface of the bioorganic stainless steel suggesting that either the peptides grafted onto the steel surface or the polypeptide composition accumulated on the steel samples. XPS analysis of the treated steel demonstrated that there was nitrogen bonding on the surface and it was a chemical bond via a previously unreported chemical interaction. The treated steel has a markedly increased contact angle (water contact angle of $65.7 \pm 4.7^{\circ}$ for nontreated steel in comparison to treated, $96.4 \pm 2.1^{\circ}$ ), which supported the observation of the wettability change of the surface, i.e. the decrease of the surface energy value after peptide treatment. The changes of the surface parameters (such as, $S_{\mathrm{a}}, S_{\mathrm{q}}, S_{\mathrm{sk}}$ and $S_{\mathrm{ku}}$ ) of the treated steel by surface analysis were observed.

\section{Introduction}

Ship and marine facilities' surfaces are easily fouled by marine fouling organisms. ${ }^{1}$ These fouling organisms cause great harm and huge economic losses to ordinary transportation and military equipment. Traditional antifouling paints releasing toxic chemicals can prevent adhesion of fouling organisms effectively. However, they also result in serious pollution to the marine environment. Currently, a few new techniques have been proposed for solving the problems of marine fouling in order to reduce biofouling of ships..$^{2-7}$

Experimental results show that homarine and its aqueous extract can inhibit the growth of the diatoms effectively, and prevent barnacle larvae and marine benthic diatoms from attaching to the surface of ships. Application of anti-adhesion compounds could lead to the development of hull coatings. ${ }^{\mathbf{8 , 9}}$ The research indicated that the drag reduction via antifouling and the alteration of surface energy of the material surface are closely related. Fouling will become difficult or defaced desorption becomes very easy when the surface energy of the

${ }^{a}$ School of Energy and Power Engineering, Wuhan University of Technology, Wuhan 430063, P. R. China. E-mail: ycq@whut.edu.cn

${ }^{b}$ School of Medicine, Keele University, Keele, Staffordshire ST5 5BG, UK

${ }^{c}$ School of Chemistry, Chemical and Life Sciences, Wuhan University of Technology, Wuhan 430070, P. R. China material is low or ultra-low, in turn, achieving the effect of drag reduction. ${ }^{10}$

In recent years, a new concept of bioorganic stainless steel has been proposed ${ }^{\mathbf{1 1}}$ in which a synthetic peptide is made to react with the metallic material surface. It was reported that such materials have a lower surface energy and are difficult to attach to by fouling organisms. Biological peptides, such as silver bonded peptides, palladium bonded peptides, and platinum bonded peptides, ${ }^{12}$ can react with metals to generate new materials. The iron oxide bonded peptide is the first polypeptide connecting a biological peptide to a metal. It is one of the synthetic peptides in the peptide library. ${ }^{13-15}$ Stainless steel is a very common metallic material, and is widely used in various industries. A new bioorganic metallic material was obtained by the reaction between the pili of microorganisms and steel. ${ }^{16-19}$ Wong et al. obtained a material with low surface energy by reacting a polypeptide with stainless steel. ${ }^{20}$ The reaction activity of stainless steel with peptides can be increased via dopamine addition. ${ }^{21}$ Later, another scholar studied the factors affecting the binding capacity to stainless steel. ${ }^{19}$ Davis et al. proved that the peptide-steel reaction led to a formal or semi-formal organic-metal covalent bond formation because stainless steel shared electrons with the dithiocycloheptane of the peptide. ${ }^{11}$ Some peptides with a linear chain do not contain a disulfide ring, but an indole group of L-tryptophan that has a cyclic chain structure, and may share electrons with metal to 
generate a new material. L-Histidine can be used as a protein tag. The imidazole group located in the residues of histidine acts as an electron donor and can form a coordinate bond by reacting with metal ions, which are immobilized on a matrix material. This group is likely to produce specific chelation with a metal ion $\left(\mathrm{Ni}^{2+}, \mathrm{Cu}^{2+}\right.$, or $\mathrm{Co}^{2+}$, etc. $)$ which is fixed on the chromatography filler. ${ }^{22}$

Previous studies on bioorganic stainless steel focused more on the identification of favourable peptides using the phage display technique or the identification of binding domains. However, the functional and surface property changes of these bioorganic stainless steels have not been investigated or reported in detail. This study fabricated one new bioorganic stainless steel, aiming to reveal the alterations of the surface parameters and functions after reaction with a specifically selected peptide. The multiple characterization assays used in this study confirm that the bioorganic stainless steel has modified surface properties.

\section{Materials and methods}

\subsection{Raw materials and sample preparation}

The peptide, denoted as BioP, was synthesized by Shanghai Science Peptide Biological Technology Co., Ltd through solid phase peptide synthesis and purified using reversed-phase high-performance liquid chromatography (HPLC). The peptide has 12 amino acids (NLNPNTASAMHV) with a molecular weight of 1268.4. Fig. 1 shows the spatial structure of the BioP.

Grade 304 stainless steel discs $(\phi 10 \times 1 \mathrm{~mm}$, with constituent elements as follows: C: $\leq 0.08 \%$; $\mathrm{Si}: \leq 1.00 \%$; Cr: $18.00-$ $20.00 \%$; $\mathrm{Mn}$ : $\leq 2.00 \%$; Ni: $8.00-11.00 \%$; P: $\leq 0.035 \%$; S: $\leq 0.030 \%$ and negligible $\mathrm{N})^{23}$ were annealed at $1040{ }^{\circ} \mathrm{C}$ for 1 hour. One surface of the discs was polished using sandpaper of five increasing grit sizes (Eagle Inc, Korean): 120\#, 240\#, 400\#, $600 \#$ and $1200 \#$ and an aqueous slurry of $0.05 \mu \mathrm{m}$ colloidal silica. The polished samples were washed using dish washing detergent and distilled water, and then immersed in $95 \%(\mathrm{v} / \mathrm{v})$ ethanol for 20 minutes on a shaker with a slow shaking rate. Then these samples were washed with distilled water, immersed in acetone for $5 \mathrm{~min}$, and rinsed with distilled water. They were placed into 12-well cell culture plates, and covered by $4 \mathrm{ml}$ phosphate buffered saline (PBS, pH 7.4) containing $10 \mu \mathrm{g}$ $\mathrm{ml}^{-1}$ peptide for the peptide reaction. The reaction plates were placed on a shaker, at a rate of $100 \mathrm{rpm}$ and were incubated at

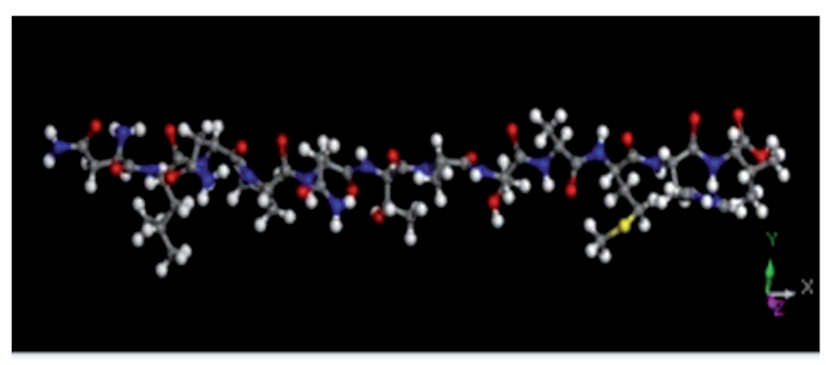

Fig. 1 The spatial structure of the peptide. room temperature for 1 hour. After the reaction, the samples were washed more than 6 times with distilled water until the peptide was not detected in the wash liquor using a spectrophotometer and dried in the drying chamber. The treated samples are denoted as BioS corresponding to the reaction products of the BioP.

\subsection{Surface morphology analysis}

A SEM equipped with an E-1045 ion sputtering device (JSM6300 , JEOL, Japan) was used to obtain the images of the sample surfaces. All samples were coated with a very thin layer of gold before analysis to improve the image contrast. SEM data were collected under an accelerating voltage of $15 \mathrm{kV}$ and a lateral resolution of $3.0 \mathrm{~nm}$. Five different locations for each sample were scanned and multiple images were collected.

\subsection{Surface composition analysis}

Infrared spectroscopy (NEXUS, USA) was used to determine the chemical composition of the sample surfaces. The spectra ranging from 4000 to $800 \mathrm{~cm}^{-1}$ with a resolution of $0.9 \mathrm{~cm}^{-1}$ were collected using the infrared spectrometer equipped with an attenuated total reflection (ATR) accessory. The background spectrum was collected first and samples were pressed against the wafer of the ATR accessories with appropriate pressure ensuring a high signal to noise ratio. The spectra for each sample were collected by scanning 128 times. The spectra were processed by baseline correction, smoothing and normalization via the OMNIC software.

A Phenom ProX SEM equipped with an EDS (Phenom, Germany) was used to conduct the elemental analysis of the sample surface. The instrument uses quad backscattered electron detectors, which can give information on the composition and morphology of the samples. The image acquisition device contains four image capture functions. The memory sample position function allows the selection of the best location automatically. Images were obtained by choosing the "full mode" under 25000 magnification conditions, and the distribution of the elements at those points were obtained via tipping some points in the samples surfaces. To confirm the presence of a specific element, the certainty values were set to greater than $90 \%$.

X-ray Photoelectron Spectroscopy (XPS) (AXIS-ULTRA DLD$600 \mathrm{~W}$, Shimadzu-Kratos, Japan) was used to examine the electronic state of the elements of the sample surfaces. The base pressure in the analytical chamber was lower than $7 \times 10^{-8}$. Monochromatic $\mathrm{Al} \mathrm{K} \alpha$ radiation source was used at a power of $450 \mathrm{~W}$. The analysis spot was $300 \times 700 \mu \mathrm{m}$. The resolution of the instrument was $0.48 \mathrm{eV}$ for $\mathrm{Ag} 3 \mathrm{~d}_{5 / 2}$ peak. The scan step was $0.05 \mathrm{eV}$. XPS spectra were generated using XPS software equipped within the instrument.

\subsection{Surface contact angle measurement and surface energy calculation}

The static contact angles of the stainless steel sample surfaces under two liquids, water and glycerol, ${ }^{24}$ were measured at $25{ }^{\circ} \mathrm{C}$ in air using a contact-angle meter (Data Physics Instruments 
CO., LTD, Filderstadt, Germany) based on the sessile drop technique. All the contact angles were determined by averaging 5 measurements for each of the samples. Surface energies of the samples were calculated via the Owens-Wendt-Rabel-Kaelble equation eqn $(1):^{25}$

$$
\begin{aligned}
(1+\cos \theta) \gamma_{\mathrm{L}}= & 2\left(\sqrt{\gamma_{\mathrm{S}}^{\mathrm{LW}} \gamma_{\mathrm{L}}^{\mathrm{LW}}}+\sqrt{\gamma_{\mathrm{S}}{ }^{+} \gamma_{\mathrm{L}}}\right. \\
& \left.+\sqrt{\gamma_{\mathrm{S}}^{-} \gamma_{\mathrm{L}}^{+}}\right)
\end{aligned}
$$

where $\theta$ is the contact angle formed by the liquid on the solid, $\gamma_{L}$ is the surface tension of the liquid, $\gamma_{\mathrm{S}}^{\mathrm{LW}}$, and $\gamma_{\mathrm{L}}^{\mathrm{LW}}$ are the Lifshitz-van der Waals components of the solid and liquid respectively, $\gamma_{\mathrm{S}}{ }^{+}$is the Lewis acid component of the solid, $\gamma_{\mathrm{L}}{ }^{+}$is the Lewis acid component of the liquid, $\gamma_{\mathrm{S}}{ }^{-}$is the base component of the solid, and $\gamma_{\mathrm{L}}{ }^{-}$is the base component of the liquid.

\subsection{Surface roughness analysis}

The surface roughness was analyzed using the surface profile measuring instrument (Huazhong University of Science and Technology, Wuhan, China), which produced multiple surface parameters. The lateral and vertical resolutions for the surface profile measuring instrument were 0.1 and $0.2 \mu \mathrm{m}$. The parameter data were collected with a diamond probe, which has a resolution of $0.01 \mu \mathrm{m}$. The rounded LISA (Laser Interferometer Space Antenna) was debugged until its centre point was at $(0,0)$, and the tip of the meter was adjusted so that the tip just touched the sample. The sampling lengths of the $X$ and $Y$ directions were $4 \mathrm{~mm}$, and the sampling intervals of the $X$ and $Y$ directions were $0.2 \mu \mathrm{m}$. The surface morphology signals of the sample were sent to the signal processing system by the laser interferometric displacement sensor. Then the sample surface parameters were calculated.

\subsection{Statistical calculations}

In each experimental set, three specimens per group for two sample groups (Nontreated and BioS), were tested. Recorded data was averaged and represented as a mean value \pm SEM. Groups were compared using independent $T$-tests. $p \leq 0.05$ was considered statistically significant. In graphs, statistical significance was indicated at two levels: $* p \leq 0.05, * * p \leq 0.01$.

\section{Experimental results}

\subsection{Surface morphology and composition of the steel samples}

After surface polishing, all steel samples showed a smooth and shining surface. After peptide treatment, there was no macroscopic alteration of the surface appearance. Fig. 2 shows the nontreated and treated samples.

3.1.1 SEM analysis. After the multiple-step polishing procedure, the smooth, flat and homogeneous surface of the steel samples has been obtained with low variation across the samples as shown in the SEM image (Fig. 3(a)).

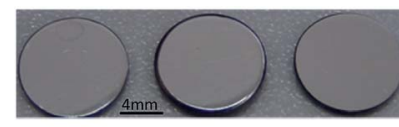

(a)

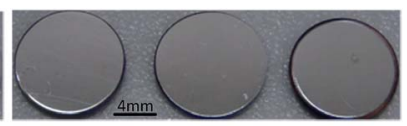

(b)
Fig. 2 Optical images of the nontreated (a) and BioS (b) samples.

However, after the reaction with the BioP, all of the stainless steel surfaces had a layer of white substance visible from the SEM images, whilst the original sample surface did not, as shown in Fig. 3(b). The layer was ascribed to the bonded peptide on the 304 stainless steel.

3.1.2 Infrared spectrum analysis. Infrared spectroscopic analysis was performed on the stainless steel surfaces of nontreated and BioS samples (Fig. 4).

A strong peak that appeared in the nontreated sample spectrum (Fig. 4(a)) in the $1100-1150 \mathrm{~cm}^{-1}$ region was the $\mathrm{Si}-\mathrm{O}-$ Si vibration. ${ }^{26,27}$ The BioS spectra showed that the surfaces of stainless steel treated with the BioP exhibited some changes. Compared with the nontreated sample, a broad peak occurred in the infrared spectra of the peptides with treated sample surfaces in the $3300-3500 \mathrm{~cm}^{-1}$ region, which proved the presence of amide A. There were 2 obvious and small peaks in the vicinity of $1610-1370 \mathrm{~cm}^{-1}$ in the BioS spectra. The result indicated that the peptides have aromatic $\mathrm{C}=\mathrm{C}$ stretching vibration. Since peptides contain peptide bonds, i.e. $\mathrm{CO}=$ $\mathrm{NR}(\mathrm{H})$, the peaks appearing around $3000 \mathrm{~cm}^{-1}$ corresponded to $\nu(\mathrm{C}-\mathrm{H})$ (including saturated or unsaturated); the peak at 1680 $\mathrm{cm}^{-1}$ to $\nu(\mathrm{C}=\mathrm{O})$ of the carbonyl group; $1450 \mathrm{~cm}^{-1}, 1380 \mathrm{~cm}^{-1}$ to an alkyl group; $\mathrm{N}-\mathrm{H}$ bending of amide II was found at 1490$1620 \mathrm{~cm}^{-1}$; 1229-1301 $\mathrm{cm}^{-1}$ was $\mathrm{C}-\mathrm{N}$ stretching and $\mathrm{NH}$ bending. All were indicators of the presence of amide groups.

3.1.3 EDS analysis. A SEM equipped with an EDS was used to observe the surface topography of the sample and to detect the elements within the substances on the sample surface. The surface topography and elemental spectra of the samples were shown in Fig. 5. The higher magnification images in Fig. 5 in comparison to those in Fig. 3 clearly demonstrate the presence of a new substance on the treated steel surfaces.

Using the EDS detector, the surface spectroscopic analysis showed that the nontreated sample mainly contained iron, chromium and nickel, the concentrations of which were $72.4 \%$, $18.2 \%$ and $7.7 \%$, respectively; and the chromium and nickel

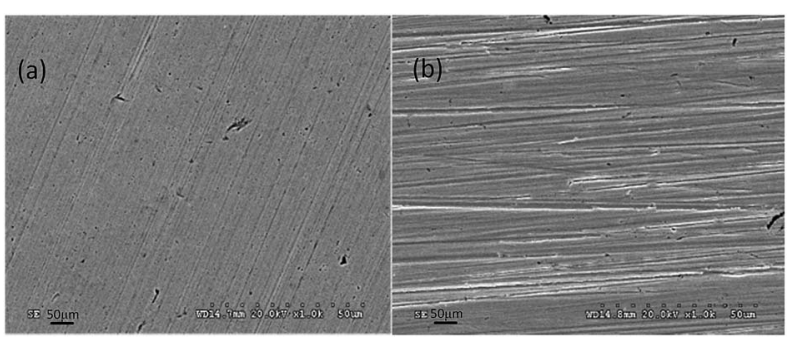

Fig. 3 SEM images of the nontreated (a) and BioS (b) samples. 

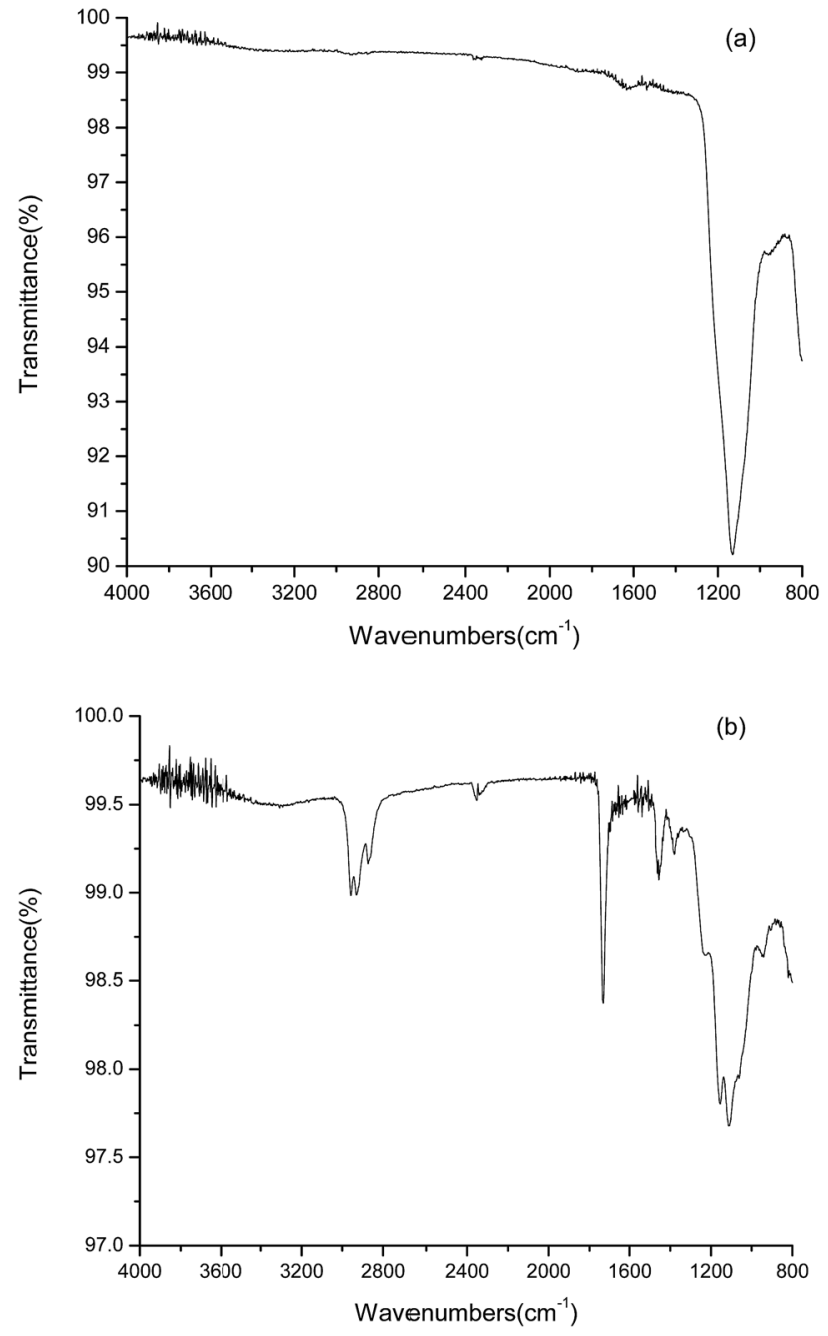

Fig. 4 Infrared spectra of the nontreated (a) and BioS (b) samples.

content ratio was about $18: 8$, a ratio in line with the proportion of the chromium and nickel content in 304 stainless steel (the formula is $0 \mathrm{Cr}_{18} \mathrm{Ni}_{9}$ ). Table 1 shows the summary of the chemical composition of the steel samples.

The surfaces of the samples treated with the peptide also contained iron, chromium and nickel. The content ratio was essentially the same as the nontreated stainless steel. However, the surfaces of the treated samples also contained $\mathrm{N}$ and Si. The element Si may come from residue chemicals after using the silicon containing sandpaper and silica slurry. Excessive nitrogen was detected only on the surfaces of the samples treated with the peptide compared to the nontreated specimen ( $\max 0.08 \%$ ). The content of $\mathrm{N}$ was about $0.9 \%$ by weight, which supported the idea that the $\mathrm{N}$ element-containing substance was formed on the sample surface after treatment with the polypeptide.

3.1.4 XPS analysis. To further identify the elements involved in the interaction and the possible bonds in the samples, XPS analysis was used to examine the electronic state of the elements in the treated samples in comparison to 304 steel. Spectra analyses of the elements of iron, chromium,
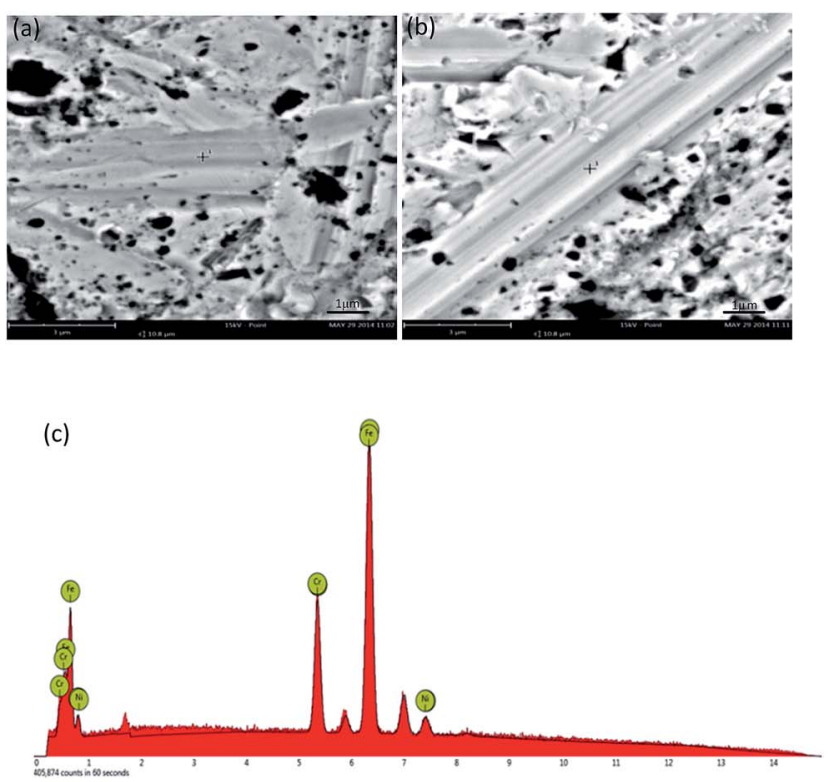

(d)

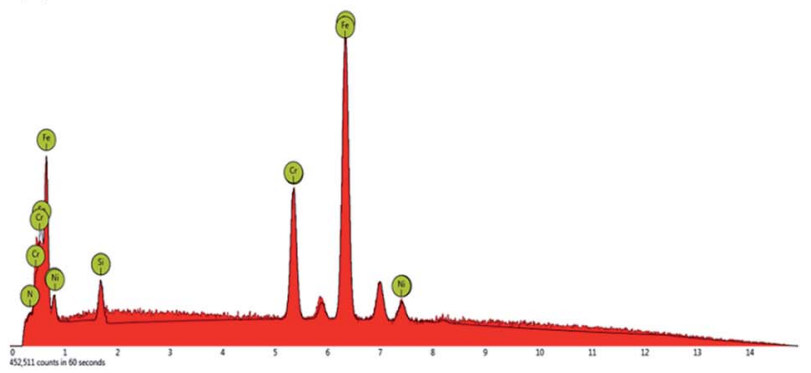

Fig. 5 SEM-EDS of the samples. SEM images of nontreated (a) and BioS (b) samples, EDS spectra of nontreated (c) and BioS (d) samples. "+" in the SEM images: representative points on the surface covered with a white substance that were used to get the EDS values.

nickel, nitrogen, and oxygen demonstrated that chromium $2 \mathrm{p}_{1 / 2}$ and $2 \mathrm{p}_{3 / 2}$ orbitals did not have an effect on the bond formation, and no electron shifts were found. No significant changes were observed in the spectra of the oxygen 1s orbital and the carbon 1s orbital. Electron shifts were found in the iron (Fig. 6(a)) and nickel (Fig. 6 (b)) $2 \mathrm{p}_{1 / 2}$ and $2 \mathrm{p}_{3 / 2}$ orbitals, which showed that iron and nickel play an important role in the formation of bonds. The 304 stainless steel contained negligible amounts of nitrogen, but a classical nitrogen orbital was found on the surface of the 304 stainless steel. Lower peaks, near the location

Table 1 The chemical composition of the steel samples from the SEM-EDS

\begin{tabular}{lrr}
\hline Element & Nontreated & \multicolumn{1}{l}{ BioS } \\
\hline Fe (\%) & $72.4 \pm 0.2$ & $71.8 \pm 0.1$ \\
Cr (\%) & $18.2 \pm 0.1$ & $17.9 \pm 0.3$ \\
Ni (\%) & $7.7 \pm 0.2$ & $7.4 \pm 0.2$ \\
Si (\%) & $1.6 \pm 0.1$ & $2.2 \pm 0.3$ \\
N (\%) & $0.02 \pm 0.01$ & $0.8 \pm 0.1$
\end{tabular}



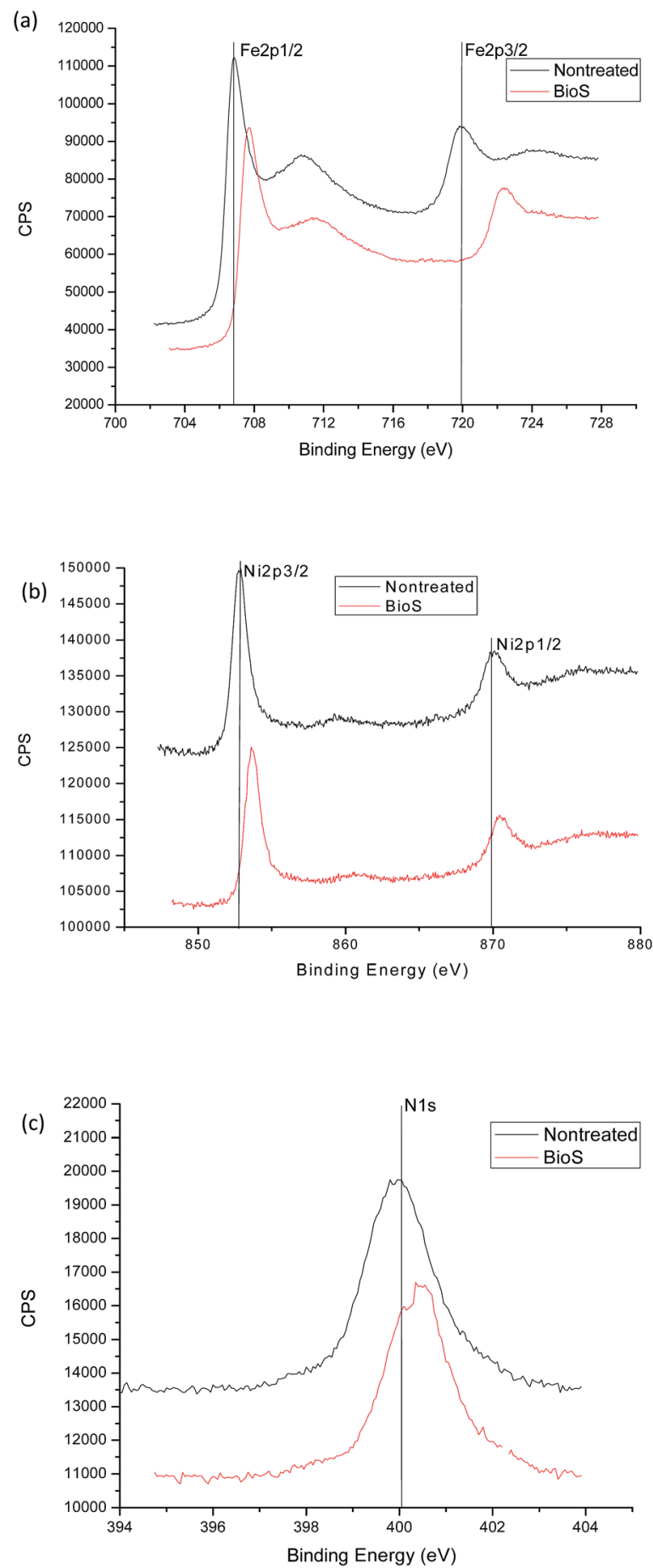

Fig. 6 XPS spectra of elemental orbital shifts of the nontreated and BioS samples. (a) Fe; (b) Ni; and (c) N.

of the unbonded nitrogen 1s orbital (Fig. 6(c)) were detected on the treated sample surfaces. This peak did not match any known shifts in nitrogen, whilst nitrogen was confirmed to be present in the samples, thus, the peak suggests that nitrogen was associated with the bonding which has not been previously described. Electrons can flow through the five-ring structure of L-proline, making it feasible that the five-ring structure could interact with the surface electrons of steel by chemically binding with them. The similar intensity of the nitrogen spectra between the nontreated and BioS samples might have resulted from two facts: the XPS tested the emitted photoelectrons from a very superficial surface (up to $2 \mathrm{~nm}$ depth) and the metal samples were not perfectly flat; and the reaction products of the peptide in the BioS samples were not distributed homogenously. Thus, the tested points of the BioS samples might have a nitrogen concentration close to the baseline level (nontreated sample), but the binding energy of the BioS was considerably larger than that in the nontreated sample, indicating a new nitrogen element in the BioS sample had appeared. It is worth mentioning that we rely on the XPS to reveal the alteration of the local chemical and physical environment affecting nitrogen, not for the quantification of nitrogen. Taken altogether, the difference between the electronic states of iron, nickel and nitrogen on the surface of the treated samples and 304 stainless steel confirm that the treated steel sample was a new material.

\subsection{Surface parameters of the steel samples}

The chemical composition analysis confirmed the presence of new substances on the surface of the treated samples. However the effects of the substances on the surfaces' physical properties, especially the surface energy and roughness are unknown. The surface contact angle and roughness parameters were measured to detect changes.

3.2.1 Contact angle. The contact angle which evaluates the hydrophobic performance of the sample surfaces, was obtained by a contact angle measuring instrument. The data shown in Fig. 7 demonstrated that the water contact angle of the treated sample surfaces significantly increased after peptide treatment.

The water contact angle of the nontreated sample surface was around $65.7 \pm 4.7^{\circ}$, and the contact angle of the BioS was $96.4 \pm 2.1^{\circ}$. The glycerol contact angle of the original sample was $53.5 \pm 4.7^{\circ}$, and the contact angle of the BioS was $83.5 \pm$ $1.2^{\circ}$. The value of the contact angle increased significantly after being treated with the peptides.

The surface energies of the samples were calculated via Owens-Wendt-Rabel-Kaelble eqn (1) and the parameters are shown in Table 2. The surface energy value of the nontreated, and BioS samples were 41.3 , and $25.0 \mathrm{mN} \mathrm{m}^{-1}$ respectively which demonstrated that the surface energy of 304 stainless steel decreased by reacting with the peptides.

3.2.2 Surface roughness. Surface roughness related parameters including surface roughness $\left(S_{\mathrm{a}}\right)$, surface root mean square deviation $\left(S_{\mathrm{q}}\right)$, skewness in the roughness profile $\left(S_{\text {sk }}\right)$ and surface height distribution kurtosis $\left(S_{\mathrm{ku}}\right)$ were measured, as summarized in Table 3 . The detailed calculations of the parameters were derived from eqn (2)-(5). ${ }^{28,29}$ The data showed

Table 2 Surface free energy constants for test liquids (in $\mathrm{mJ} \mathrm{m}^{-2}$ )

\begin{tabular}{llccc}
\hline Liquid & $\gamma_{\mathrm{L}}$ & $\gamma_{\mathrm{L}}^{\mathrm{LW}}$ & $\gamma_{\mathrm{L}}{ }^{+}$ & $\gamma_{\mathrm{L}}{ }^{-}$ \\
\hline Water & 71.8 & 21.8 & 25.5 & 25.5 \\
Glycerol & 64.0 & 34.0 & 3.92 & 57.4
\end{tabular}


Table 3 Surface parameters of the steel samples

\begin{tabular}{lllll}
\hline Number & $S_{\mathrm{a}}(\mu \mathrm{m})$ & $S_{\mathrm{q}}(\mu \mathrm{m})$ & $S_{\mathrm{sk}}$ & \multicolumn{1}{l}{$S_{\mathrm{ku}}$} \\
\hline Nontreated & $0.945 \pm 0.053$ & $1.496 \pm 0.007$ & $4.077 \pm 0.236$ & $37.9 \pm 2.5$ \\
BioS & $1.187 \pm 0.004$ & $1.679 \pm 0.056$ & $0.720 \pm 0.016$ & $14.8 \pm 1.8$
\end{tabular}

that the surface roughness value $\left(S_{\mathrm{a}}\right)$ of the samples increased after peptide treatment with the Bios. Surface root mean square deviation $\left(S_{\mathrm{q}}\right)$ was used to express the root mean square of the surface roughness deviated from the reference plane. It was shown that the value of $S_{\mathrm{q}}$ increased after the BioP treatment. Skewness in the roughness profile $\left(S_{\mathrm{sk}}\right)$ is a measure of the symmetry of the amplitude distribution curve about the mean line. Skewness indicates whether the surface consists of mainly peaks or valleys or an equal combination of both, a negative $S_{\mathrm{sk}}$ value indicates a greater distribution of valleys about the mean line as the amplitude distribution curve is skewed above the mean line. It was found that the $S_{\mathrm{sk}}$ of the samples decreased after the BioP treatment. Surface height distribution kurtosis $\left(S_{\mathrm{ku}}\right)$ describes the amplitude distribution curve for the points of the surface profile. The topographic height of the surface will be in the centre of the base plane when the value of $S_{\mathrm{ku}}$ is greater than 3.0. It is better that the value of $S_{\mathrm{ku}}$ is close to 3 . The value of the samples dropped after the peptide treatment.

$$
\begin{gathered}
S_{\mathrm{a}}=\frac{1}{M N} \sum_{k=0}^{M-1} \sum_{l=0}^{N-1}\left|z\left(x_{k}-y_{l}\right)-u\right| \\
S_{\mathrm{q}}=\sqrt{\frac{1}{M N} \sum_{k=0}^{M-1} \sum_{l=0}^{N-1}\left(z\left(x_{k}-y_{l}\right)-u\right)^{2}} \\
S_{\mathrm{sk}}=\frac{1}{M N S_{\mathrm{q}}{ }^{3}} \sum_{k=0}^{M-1} \sum_{l=0}^{N-1}\left(z\left(x_{k}-y_{l}\right)-u\right)^{3} \\
S_{\mathrm{ku}}=\frac{1}{M N S_{\mathrm{q}}{ }^{4}} \sum_{k=0}^{M-1} \sum_{l=0}^{N-1}\left(z\left(x_{k}-y_{l}\right)-u\right)^{4}
\end{gathered}
$$

In eqn (2)-(5), $u$ is the average height of the calculated region, $M$ is the collected points in the $x$ direction of the reference plane, $N$ is the collected points in the $y$ direction of the reference plane, $x_{k}$ is the concavo-convex level in the $x$ direction of the base surface, and $y_{l}$ is the concavo-convex level in the $y$ direction of the base surface.

\section{Discussion}

A few peptides have been reported to react with stainless steel. ${ }^{11,14,16}$ In this study, we selected the BioP to react with steel samples and conducted multiple characterisations to investigate the treated samples. Although the peptide has been studied by Zuo and Vreuls, ${ }^{17,30}$ there was no systematic study on the treated steel samples. Reaction with the peptide under mild conditions resulted in alteration of the metal surfaces' chemical and physical properties. A new substance was generated on the surface of the samples, which has been detected by multiple chemical and physical analysis assays. A white particulate substance was visible on the SEM images, where the nitrogen element associates with the new white substance and the changed FTIR spectra and XPS spectra of the treated steel surface chemically confirmed the presence and composition of the new substance. The physical property changes including the water contact angle and surface roughness parameters further supported the observations. In our study, the reacted steel samples have been washed vigorously before characterisation. Thus, the physical trapping of the peptide on the steel sample surface was low. All the results provide strong evidence that a bioorganic metallic material has been formed on the treated steel samples.

SEM analysis is a convenient and powerful technique to study surface topographic changes, which has been used to study stainless steel surfaces modified by peptides. ${ }^{11,21}$ In combination with EDS analysis, we not only observed the new substance on the treated steel surfaces, but also detected their composition using nitrogen as the marker for the peptide grafting degree. All peptides have unique peptide bonds, i.e. $\mathrm{CO}=\mathrm{NR}(\mathrm{H})$. The reaction extent of stainless steel and peptides can be reflected by the $\mathrm{N}$ content. ${ }^{11,21} \mathrm{EDS}$ analysis is an accurate technique to determine the composition of the surface substance of the sample. In the treated steel sample surfaces, $\mathrm{Fe}, \mathrm{Cr}$ and Ni component proportions have been detected. Their concentrations were same as the component ratio of the original stainless steel. The element nitrogen on the surface proved that the stainless steel surface treated with the peptide was comprised of a novel nitrogen-containing substance, and the content is relatively stable (Table 1). The new steel sample generated by the reaction between the peptide and stainless steel can be classed as bioorganic stainless steel.

ATR-FTIR has been used to study the surfaces treated with the peptide. ${ }^{31,32}$ Peptide bonds, carbon-hydrogen bonds, and carbon-oxygen bonds, etc. were found on the surface of the treated samples in our study (Fig. 4). There were 2 obvious and some small valleys in the vicinity of $1610-1370 \mathrm{~cm}^{-1}$ in the BioS spectra. The result indicated that the peptide has aromatic $\mathrm{C}=\mathrm{C}$ stretching vibration. $\mathrm{N}-\mathrm{H}$ bending of amide II was found at $1490-1620 \mathrm{~cm}^{-1} ; 1229-1301 \mathrm{~cm}^{-1}$ is C-N stretching and $\mathrm{NH}$ bending. ${ }^{33}$ These spectra suggested that the occurrence of a reaction between steel and the peptide generated a substance containing organic ingredients which may be obtained by the joining of the peptide with the free electrons of stainless steel. The treated steel material exhibited new spectral peaks which did not belong to the original steel material. Hence, the peptide has been physically and chemically bonded to the steel surfaces through the active groups and elements on the steel. The FITR and XPS spectra of the treated sample supported the EDS results. However, the specific reaction mechanisms are complex and will be studied in subsequent experiments.

The contact angle is determined by the surface morphology and chemical substances. ${ }^{34}$ The generation of a new substance on the sample surface, is the main cause that led to the changes in the surface parameters. According to Young's equation,,$^{35}$ the surface energy of the samples reduced when the contact angles 


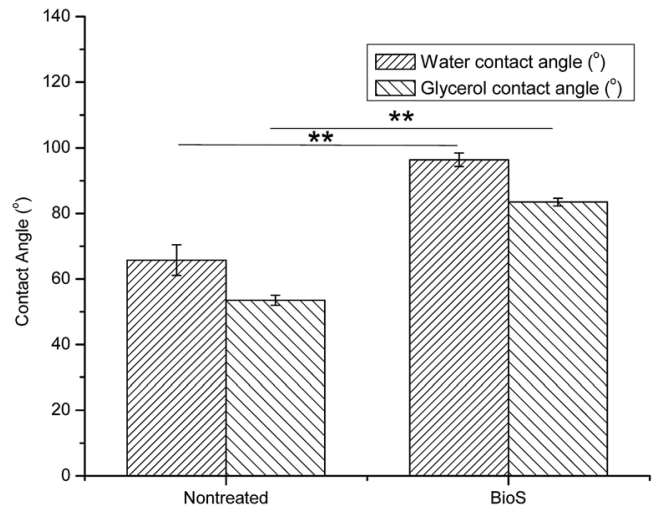

Fig. 7 Contact angles of the steel samples' surface. ${ }^{* \star} p<0.001$.

were increased which is consistent with the calculation results. Thus, contact angle changes in samples can be used to analyse changes in the surface energy of samples qualitatively. As can be seen from Fig. 7 , the value of the contact angle increased significantly $(p<0.001)$ in comparison to the nontreated sample. Thus, the hydrophobic properties of the steel surfaces increased. However, the amount of improvement in the contact angle or surface energy was not big, and further investigations to generate a new generation of antifouling materials are required. The increase in the sample contact angles could be partially due to the surface topographic change after peptide bonding. The changes in the contact angle of the steel sample indicated that the reaction with the BioP can considerably influence the steel surface.

Surface morphology has a greater effect on the contact angle compared to the chemical composition..$^{34}$ In this study, it was found that the sample surface became smoother after treating with the peptide (Table 3). The changes of the surface roughness parameters were mainly caused by the new substance generated on the surface of the sample. The steel sample contained numerous grain boundaries, and the BioS has been shown to bind with higher adhesive force to grain boundaries compared to regions within grains. ${ }^{36}$ The majority of the reactions probably happened in the trough of the surface, and the complex structure of the new substance on the surface led to the smoother surface after the Bios bonded with stainless steel.

\section{Conclusions}

In summary, we successfully produced a new material via the reaction between peptides and the 304 stainless steel, which is also known as bioorganic stainless steel. The material has considerably different physical and chemical properties compared to the original sample. Bioorganic stainless steel has a higher contact angle than unmodified stainless steel, and the surface became smoother. The new bioorganic material has potential for further optimization into a new type of material for construction of hulls, and submarine pipelines, etc. to reduce drag caused by sea water because of its new surface properties.

\section{Acknowledgements}

This work was financially supported by the National Natural Science Foundation of China (No. 51375355 and No. 51422507) and the Program of Introducing Talents of Discipline to Universities (B08031). The authors gratefully acknowledge the technical assistance of Mr Zhong Cheng in relation to the infrared spectrum and SEM analysis. We also would like to thank the Shanghai Science Peptide Biological Technology Co., Ltd for synthesizing the peptides.

\section{Notes and references}

1 A. S. Clare, New Sci., 1995, 145, 38.

2 C. Neinhuis and W. Barthlott, Ann. Bot., 1997, 79, 667.

3 T. Wagner, C. Neinhuis and W. Barthlott, Acta Zool., 1996, 77, 213.

4 L. Feng, S. H. Li, Y. C. Li, H. J. Li, L. J. Zhang, J. Zhai, Y. L. Song, B. Q. Liu, L. Jiang and D. B. Zhu, Adv. Mater., 2002, 14, 1857.

5 A. B. Kesel, A. Martin and T. Seidl, Smart Mater. Struct., 2004, 13, 512 .

6 N. A. Patankar, Langmuir, 2004, 20, 8209.

7 A. T. Holohan, M. H. George, J. A. Barrie and D. J. Parker, Polymer, 1992, 33, 852.

8 D. Rittschof, I. R. Hooper, E. S. Branscomb and J. D. Costlow, J. Chem. Ecol., 1985, 11, 551.

9 S. Tsukamoto, H. Kato, H. Hirota and N. Fusetani, Tetrahedron Lett., 1996, 37, 1439.

10 S. Abarzua and S. Jacubowski, Mar. Ecol.: Prog. Ser., 1995, 123, 301.

11 E. M. Davis, D. Y. Li and R. T. Irvin, Biomaterials, 2011, 32, 5311.

12 M. Sarikaya, C. Tamerler, A. K. Jen, K. Schulten and F. Baneyx, Nat. Mater, 2003, 2, 577.

13 S. Brown, Proc. Natl. Acad. Sci. U. S. A., 1992, 89, 8651.

14 U. O. S. Seker and H. V. Demir, Molecules, 2011, 16, 1426.

15 S. Brown, Nat. Biotechnol., 1997, 15, 269.

16 A. Héquet, V. Humblot, J. M. Berjeaud and C. M. Pradier, Colloids Surf., B, 2011, 84, 301.

17 R. J. Zuo, D. Örnek and T. K. Wood, Appl. Microbiol. Biotechnol., 2005, 68, 505.

18 C. L. Giltner, E. J. van Schaik, G. F. Audette, D. Kao, R. S. Hodges, D. J. Hassett and R. T. Irvin, Mol. Microbiol., 2006, 59, 1083.

19 P. M. Stanley, Can. J. Microbiol., 1983, 29, 1493.

20 W. Y. Wong, C. McInnes, B. D. Sykes, W. Paranchych, R. T. Irvin and R. S. Hodges, Biochemistry, 1995, 34, 12963.

21 J. Kang, M. Sakuragi, A. Shibata, H. Abe, T. Kitajima, S. Tada, M. Mizutani, H. Ohmori, H. Ayame, T. Il Son, T. Aigaki and Y. Ito, Mater. Sci. Eng., C, 2012, 32, 2552.

22 J. B. Ruan and Y. Z. Mei, Biotechnol. Bull., 2012, 6, 49.

$23 \mathrm{http} / / /$ www.azom.com/article.aspx?ArticleID $=965$.

24 M. Michalski, J. Hardly and B. Saramago, J. Colloid Interface Sci., 1998, 208, 319.

25 F. M. Namen, E. Ferrandini and J. G. Junior, J. Appl. Oral Sci., 2011, 19, 517. 
26 H. Amekura, N. Umeda, N. Okubo and N. Kishimoto, Nucl. Instrum. Methods Phys. Res., Sect. B, 2003, 206, 1101.

27 L. N. He, Vac. Sci. Technol., 2001, 21, 60.

28 B. X. Wang, F. F. Chen and Y. Dong, Metrology for Micro- and Nanotechnology, Tsinghua University Press, Beijing, 2006.

29 A. J. Scardino, D. Hudleston, Z. Peng, N. A. Paul and R. de Nys, Biofouling, 2009, 25, 83.

30 C. Vreuls, G. Zocchi, A. Genin, C. Archambeau, J. Martial and C. V. Weerdt, J. Inorg. Biochem., 2010, 104, 1013.

31 A. M. Donia, A. A. Atia, A. M. Daher, O. A. Desouky and E. A. Elshehy, J. Radioanal. Nucl. Chem., 2011, 290, 297.
32 J. Wang, N. Huang, P. Yang, Y. X. Leng, H. Sun, Z. Y. Liu and P. K. Chu, Biomaterials, 2004, 25, 3163.

33 M. Carbonaro and A. Nucara, Amino Acids, 2010, 38, 679.

34 J. D. Wang, Y. Yu and D. R. Cheng, Chin. Sci. Bull., 2006, 51, 2097.

35 M. O. Goebel, J. B. Bachmann, S. K. Woche, W. R. Fischer and R. Horton, Soil Sci. Soc. Am. J., 2004, 68, 383.

36 B. Yu, E. M. Davis, R. S. Hodges, R. T. Irvin and D. Y. Li, Nanotechnology, 2008, 19, 8. 